\title{
Cause of Death of Covid-19 Patients
}

\author{
Harsh Vijay Meshram ${ }^{1}$, Manju Chandankhede ${ }^{2}$ and Swarupa Chakole ${ }^{3}$ \\ ${ }^{1}$ First Year MBBS Student, Datta Meghe Medical College, India \\ ${ }^{2}$ Department of Biochemistry Datta Meghe Medical College, Shalinitai Meghe \\ Hospital and Research Centre, Nagpur, India \\ ${ }^{3}$ Department of Community Medicine Jawaharlal Nehru Medical College, Datta \\ Meghe Institute of Medical Sciences Sawangi (Meghe), Wardha, India \\ Corresponding author email:drmanjusc@gmail.com
}

\section{ABSTRACT}

According to the WOLRD HEALTH ORGANIZATION (WHO) there are 142,557,268 confirmed cases of covid-19 globally (as of 22 April 2021). The death toll of 3,037,398 cases has been confirmed. India is one of the country to have highest cases of the covid-19. The SARS-CoV-2 infection are asymptomatic while most cause mild illness with respiratory and fever, cough, chills, sore throat. Many of the people doesn't know about actual critical level that can happen if this disease doesn't treat as soon as possible. The cancer patients are relatively are more prone to death by covid-19 virus. Since the individual with active cancer has less immunity to defend the body. Covid-19 infection increases the chances of organ related complication as the patients has gone through cancer treatment like chemotherapy and radiation therapy. Weakness of COVID-19 (homicide) is a condition based on age, according to the hyperfunction theory of quasi designed aging, which links it to other age-related diseases. Inflammation and immunity, as well as hyperinfigueation, hyperthrombosis, and cytokine storms, are both linked to the risk of COVID-19.

KEY WORDS: SEVERE ACUTE RESPIRATORY SYNDROME, COVID-19 VIRUS, CORONA VIRUS, DEATH BY COVID-19, RTPCR, DEATH TOLL, ORGAN FAILURE, HAEMOTHORAX, ASTHMA.

\section{INTRODUCTION}

The covid-19 or corona virus has spread across the globe in a short period of time creating havoc and distress in the life of the people. According to the WOLRD HEALTH ORGANIZATION (WHO) there are 142,557,268 confirmed cases of covid-19 globally (as of 22 April 2021). The death toll of 3,037,398 cases has been confirmed. India is one of the country to have highest cases of the covid19. The SARS-CoV-2 infection are asymptomatic while most cause mild illness with respiratory and fever, cough, chills, sore throat. Many of the people doesn't know about

Biosc Biotech Res Comm P-ISSN: 0974-6455 E-ISSN: 2321-4007

\section{crossef}

Identifiers and Pagination

Year: 2021 Vol: 14 No (7) Special Issue

Pages:76-79

This is an open access article under Creative

Commons License Attribn 4.0 Intl (CC-BY).

DOI: $h t t p: / / d x$.doi.org/10.21786/bbrc/14.7.18 actual critical level that can happen if this disease doesn't treat as soon as possible.

The risk of death of COVID-19 is largely influenced by age and past health conditions. Patients over the age of 65, as well as those with chronic comorbidities such as heart disease, high blood pressure, diabetes, and pulmonary disease, are at greater risk of developing a serious and catastrophic disease. These links may make it difficult to say how much COVID-19 or existing health conditions affected the time of a patient's death. Detailed information on the cause and mechanism of death, as well as the extent of humor in cases with fatal consequences, is still lacking, precluding accurate assessment of the dangerous presence of COVID-19.

The death are increasing due to the new strains and virus adapting to new environment of antibodies inside the human body. 
According to the recent report, India has crossed 3 lakhs covid-19 cases in the last 24 hours. India has confirmed 15.9 M cases till dates and the death toll of 184,672 cases. Maharashtra has the highest amount of covid cases in India currently $4.03 \mathrm{M}$ confirmed cases and death toll of 61,911 followed by Kerala, Karnataka, Tamilnadu and Andrapradesh. Since the corona virus outbreak a fraction of the population is at higher risk. The geriatric patient and the children are more vulnerable to the infectious diseases like the covid-19 virus.

Figure 1: Symptoms: Most Common Symptoms

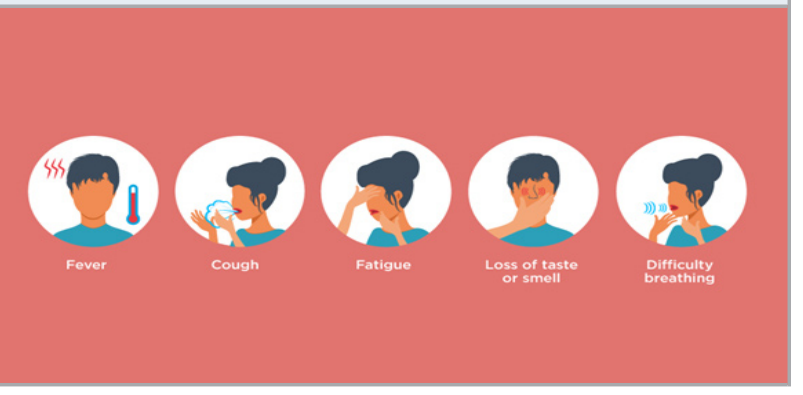

The cancer patients are relatively are more prone to death by covid-19 virus. Since the individual with active cancer has less immunity to defend the body. Covid-19 infection increases the chances of organ related complication as the patients has gone through cancer treatment like chemotherapy and radiation therapy. Fever (99 percent), fatigue (70 percent), cough (59 percent), loss of appetite (40 percent), body pain ( 35 percent), shortness of breath (31 percent), and phlegm or phlegm are the most common symptoms recorded by Chinese researchers and scientists (27 percent). The new corona virus is more dangerous than the flu virus. Coronavirus causes more serious illness and death than the flu virus (Blagosklonny MV et al., 2020).

- High body temperature

- Coughing that is dry

- exhaustion

- Pains and aches

- Diarrhea is a common ailment.

- Conjunctivitis is a condition that affects the eyes.

- Pain in the head

- Taste / olfactory loss

- Skin rashes or discoloration of the fingers or toes

- Serious symptoms

- Shortness of breath

- Chest pain

- Expression or movement impairment(Rakesh Kumar Jha et al., 2020)

Corona virus/ Covid-19 is the major health problem causing respiratory diseases in humans. It is spreading rapidly around the world. In December 2019, the first case of covid-19 was discovered in WUHAN, CHINA. SYNDROME SOLNDROME CORONA VIRUS 2 HEART is an old virus Covid -19. (SARS-CoV-2). Coronavirus is a member of the viral family Coronaviridae. The source of the covid-19 virus is unclear, but many scientists believe that bats, penguins, or seafood may play a role in the virus, which can spread to humans in a zoonotic way. Covid-19 has a high level of pathogenicity and distribution. It could be transmitted from human to human by droplets and contact it primarily spread due to through respiratory droplet while coughing or sneezing (Triggle CR et al., 2021).
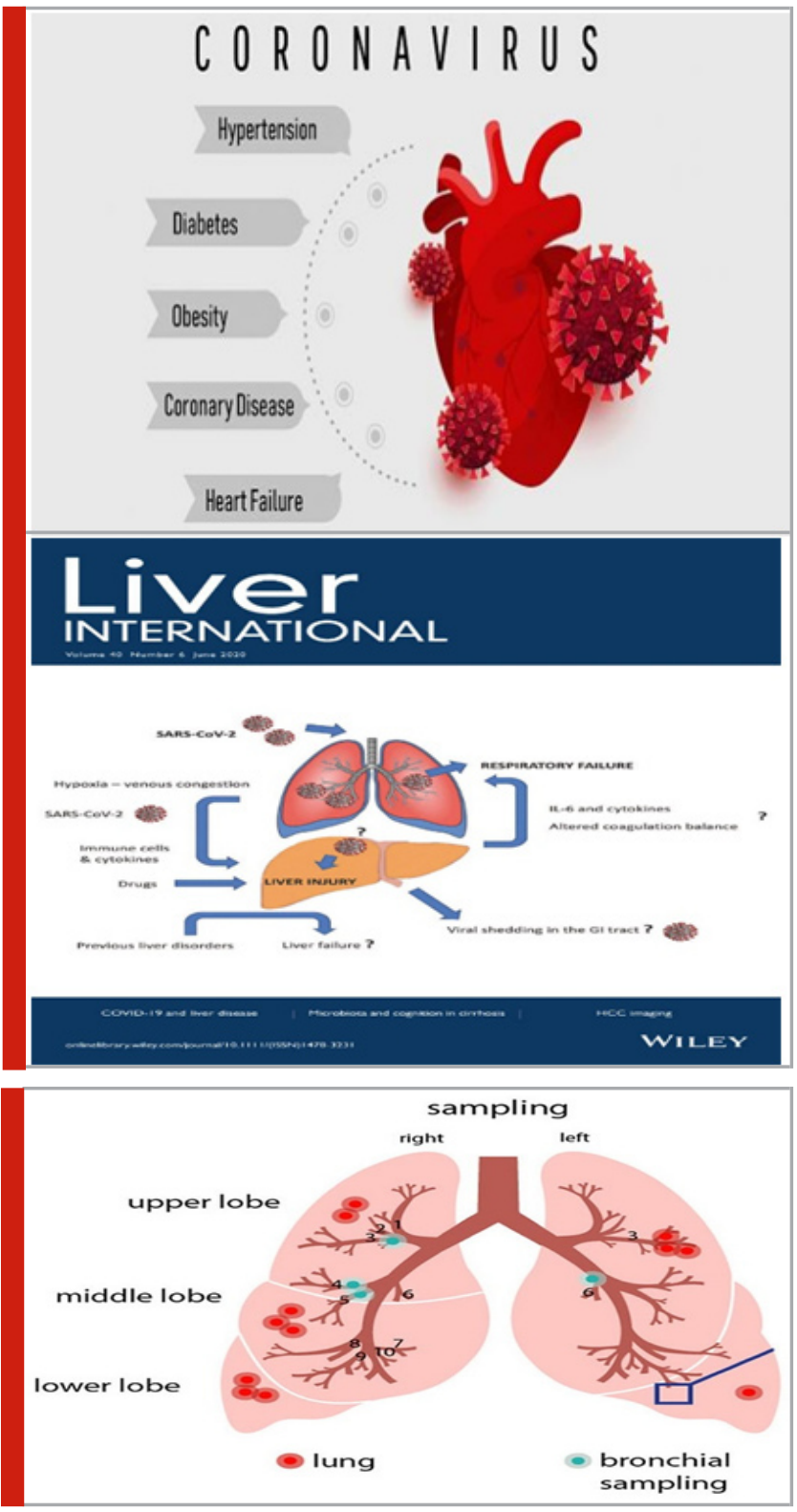

Covid-19 affects the upper and upper respiratory tract, including the nasal passages, nose, and throat, as well as the windpipe and lung alveoli. As the virus reaches the host cell through the enzyme that converts angiotensin, the lungs are the most affected organs in it. The lungs are inflamed, making breathing difficult. Covid-19 is more dangerous than pneumonia. Covid-19 pneumonia worsens acute respiratory disease, suppressing lung fibrillation. Dry cough, shortness of breath, and high heart rate are all symptoms of ARDS. The virus causes damage to the walls of the alveolus and capillary and linings. The dead cell, a plasma protein, accumulates in the lungs and strengthens the alveoli membrane, making 
breathing difficult and ultimately leading to death. SARSCoV-2, a new type of corona virus that was discovered in 2019, faced a difficult challenge. Thousands of people are infected with the virus, which, if left untreated, can lead to death (Vodnar DC et al., 2020).

People with higher age and new born are prone to this disease as it affect the respiratory system and disbalance the proper function of body by fever, cold, cough etc. The main cause of death is due to the oxygen level drop suddenly as the lack of oxygen the patient die in few minutes to hours. In many patients, comorbidities such as high blood pressure, heart disease, and obesity were common. Our results show that in many of the decedents, the causes of death were directly linked to COVID-19, rather than the immediate effect of existing health conditions and comorbidities. Because of this, we believe that most of the patients died from COVID-19, while the existing health conditions played a small role in death.

Covid-19 not only affect the lungs but also the other vital organ such as Pinkeye

- Rashes

- Liver problem or liver damage

- Heart problems

- Kidney damage

- Dangerous blood clot including in their legs, lungs and arteries. Some clots may cause stroke.

- Gastrointestinal system damage causing water loss and diarrhea.

Covid-19 also affect the brain directly or indirectly by encephalitis or by the lack of oxygen in the brain (hypoxia) . if any one gets covid-19 positive most of the infections are mild but the older you are, the higher your risk of severe illness because of the thymus gland which also known as the throne of immunity, starts to shrink after puberty slowly it gets deposited by the fat which cause decrease in the immune responses or the immunity of the body. The cancer patient, the people who above the age 60 are not only vulnerable to corona virus but the person who are obese or having a sedentary lifestyle are likely to get infected by the corona virus .the patient who has undergone a organ transplant and has weakened immune system due to the immunosuppressive drug , the patients who has Chronic obstructive pulmonary disease (COPD), the persons who has serious heart condition like the Coronary artery disease, myocardial ischemia or undergone any heart surgery such as angioplasty, Bypass surgery etc., the persons suffering from disease related to blood like the sickle cell disease, leukemia (blood cancer).

There are some condition which can lead to the severe illness by the covid-19 virus like Cystic fibrosis which make the breathing painful, Smoking -it causes the chronic inflammation in the lung, lung cancer, bronchitis and emphysema which make the persons more vulnerable to the virus thus the life expectancy of the smoker is less than that of a Non-smoker. The patients who suffering from the diabetes are also prone to this virus which causes haemothorax (the accumulation of the blood in the lung) (Sridhar S et al., 2021).

Findings: In 31 cases (97\%), SARS-CoV-2 infection was confirmed by nasopharyngeal RT-PCR, and in the remaining 1 case, SARS-CoV-2 spike-protein spikeprotein breakdown in lung -3). At the age of 68 years (range: 30-100), the racially diverse group consisted of 22 men and 10 women. Coughing (17 [55 percent]), shortness of breath (26 [81 percent]), and low-grade fever were the most common symptoms (17 percent [55 percent)). Thirty-one patients (97\%) had one comorbidity (mean $=$ four). Twenty-eight patients $(88 \%)$ have multiple thromboembolic diseases, as well as alveolar damage (30 [94\%]), diabetic nephropathy (17 [57\%]), and severe tubular injury.

\section{DISCUSSION}

Transmission: Respiratory droplets and interaction with respiratory secretions and saliva are the primary Routes of transmission. Another mode of transmission may be aerosol particles. SARS CoV-2 can survive for hours todays on various surfaces, but transmission through Respiratory droplets is much more common than via fomites. For several weeks after the case, faecal shedding has been observed.

Treatment: Children with SAR-COV (COVID-19) should receive compassionate treatment in the same way as adults should. Bedrest and adequate calorie and water consumption are among the guidelines .Patients with hypoxia should receive oxygen therapy. Antibiotics can be used only when a child has a bacterial co-infection. In June 2020, a phase 2/3trial of remdesivir (CARAVAN) was started in children with moderate-to-severe COVID19 to assess safety, tolerability ,pharmacokinetics ,and efficacy. CARAVAN is a single-arm, open-label trial of remdesivir in children aged one to eighteen years. BamlanivimabisanIgG1 monoclonal antibody (mAb) that neutralizes SARS-spikeCoV-2's protein .It Is intended to prevent and treat COVID-19 by preventing Viral attachment and entry into human cells and there by neutralizing the virus. Different studies on related morbidities8,9 and Covid10-14 were reviewed.

\section{CONCLUSION}

The autopsy conducted on covid-19 patient majority of them have pulmonary thrombosis and alveoli damaged severely. The patients of higher age have more effect than the people belonging to the mid -age. Weakness of COVID19 (homicide) is a condition based on age, according to the hyperfunction theory of quasi-designed aging, which links it to other age-related diseases. Inflammation and immunity, as well as hyperinfigueation, hyperthrombosis, and cytokine storms, are both linked to the risk of COVID19. Anti-aging drugs such as rapamycin have been shown to slow aging and age-related diseases, which may reduce the risk of COVID-19. 


\section{REFERENCES}

Acharya, Sourya, Samarth Shukla, And Neema Acharya (June 2020). Gospels Of A Pandemic- A Metaphysical Commentary On The Current Covid-19 Crisis.” Journal Of Clinical And Diagnostic Research 14, No. 6: 0a01-2. Https://Doi.Org/10.7860/Jcdr/2020/44627.13774.

Arora, Devamsh, Muskan Sharma, Sourya Acharya, Samarth Shukla, And Neema Acharya (October 26, 2020). India In 'Flattening The Curve' Of Covid-19 Pandemic - Triumphs And Challenges Thereof." Journal Of Evolution Of Medical And Dental SciencesJemds 9, No. 43: 3252-55. Https://Doi.Org/10.14260/ Jemds/2020/713.

Bawiskar, Nipun, Amol Andhale, Vidyashree Hulkoti, Sourya Acharya, And Samarth Shukla ((November 16, 2020)). Haematological Manifestations Of Covid-19 And Emerging Immunohaematological Therapeutic Strategies." Journal of Evolution of Medical And Dental Sciences-Jemds 9, No. 46: 3489-94. Https://Doi. Org/10.14260/Jemds/2020/763.

Blagosklonny MV (2020 Jun). From Causes of Aging To Death From Covid-19. Aging (Albany Ny);12;12(11):10004-10021.

Butola, Lata Kanyal, Ranjit Ambad, Prakash Keshaorao Kute, Roshan Kumar Jha, And Amol Dattaroa Shinde (September 28, 2020). The Pandemic Of 21st Century - Covid-19." Journal of Evolution Of Medical And Dental Sciences-Jemds 9, No. 39: 2913-18. Https://Doi. Org/10.14260/Jemds/2020/637.

Coronavirus Disease (Covid-19) Outbreak Situation. Available At: Https://Www.Who.Int/Emergencies/ Diseases/Novel-Coronavirus-2019

Godhiwala, Parth, Sourya Acharya, Gaurav Jagtap, Arvind Bhake, And Samarth Shukla (February 8, 2021). Leukemoid Reaction In A Covid-19 Patient."
Journal Of Evolution Of Medical And Dental SciencesJemds 10, No. 6: 399-400. Https://Doi.Org/10.14260/ Jemds/2021/88.

Https://Www.Worldometers.Info/Coronavirus/Country/ India/

Khatib, N., S. Gaidhane, A. Gaidhane, And Zahiruddin Quazi Syed. "M-Health Intervention For Type Ii Diabetes Mellitus Patients In Indian Rural Areas.” Diabetes Technology \&t Therapeutics 16, No. 1 (February 1, 2014): A95-96.

Rakesh Kumar Jha, Pradip Jain, Ranjit S. Ambad, Nandkishor (2020). The Origin, Transmission And Mortality Of Corona Virus. Jcr;7(10):93-96. Doi:10.31838/ Jcr.07.10.23

Singhal, S., Zahiruddin Quazi Syed, S. N. Mahajan, S. K. Diwan, And A. Gaidhane (December 2009). Reasons For Non-Compliance Among Patients Treated Under Revised National Tuberculosis Control Programme (Rntcp) And Their Treatment Outcome After Structured Counselling. Asian Pacific Journal of Tropical Medicine 2, No. 6: 48-51.

To Kk, Sridhar S, Chiu Kh, et al (2021). Lessons Learned 1 Year After Sars-Cov-2 Emergence Leading To Covid19 Pandemic. Emerg Microbes Infect;10(1):507-535.

Triggle Cr, Bansal D, Ding H, et al (2021). A Comprehensive Review Of Viral Characteristics, Transmission, Pathophysiology, Immune Response, And Management Of Sars-Cov-2 And Covid-19 As A Basis For Controlling The Pandemic. Front Immunol;12:631139. Published 2021 Feb 26. Doi:10.3389/Fimmu.2021.631139

Vodnar Dc, Mitrea L, Teleky Be, et al (2020). Coronavirus Disease (Covid-19) Caused By (Sars-Cov-2) Infections: A Real Challenge For Human Gut Microbiota. Front Cell Infect Microbiol;10:575559. Published 2020 Dec 9. Doi:10.3389/Fcimb.2020.575559 